
in Smart Grids"

YEF-ECE International Young Engineers Forum on Electrical and Computer Engineering, Almada Portugal.

ISBN: 978-1-5386-1503-4

ISSN: 10.1109/YEF-ECE.2018.8368936

This material is posted here with permission of the IEEE. Such permission of the IEEE does not in any way imply IEEE endorsement of any of Group of Energy and Power Electronics, University of Minho, products or services. Internal or personal use of this material is permitted. However, permission to reprint/republish this material for advertising or promotional purposes or for creating new collective works for resale or redistribution must be obtained from the IEEE by writing to pubs-permissions@ieee.org. By choosing to view this document, you agree to all provisions of the copyright laws protecting it.

(C) 2014 IEEE 


\title{
A Novel Two-Switch Three-Level Active Rectifier for Grid-Connected Electrical Appliances in Smart Grids
}

\author{
Vítor Monteiro ${ }^{1}$, Tiago J. C. Sousa ${ }^{1}$, Mohamed Tanta ${ }^{1}$, Simão Almeida ${ }^{2}$, Rui Gomes ${ }^{2}$, João L. Afonso ${ }^{1}$ \\ ${ }_{1,2}$ ALGORITMI Research Centre - University of Minho, Guimarães - Portugal \\ ${ }^{1}\{$ vmonteiro $\mid$ tsousa $\mid$ mtanta $\mid$ jla\}@dei.uminho.pt \\ ${ }^{2}\{a 71466 \mid$ a72043\}@alunos.uminho.pt
}

\begin{abstract}
A novel topology of two-switch three-level active rectifier (TSTL-AR) is proposed in order to connect electrical appliances to smart grids considering power quality aspects. The proposed active rectifier is presented as a powerful solution to mitigate the negative effects of current harmonic distortion of the diode-bridge rectifiers, besides the ability of operating with unitary power factor. These aspects are particularly relevant considering the new paradigm of smart grids, where almost all the electrical appliances should be controlled in order to comply normative impositions of power quality. In addition, active rectifiers are also fundamental devices regarding the electric vehicle battery chargers, which are a new and significant class of electrical appliances for smart grids. In this paper, a comprehensive and detailed description of the novel topology of TSTL-AR is presented and compared with the classical power factor correction topology. Along the paper, it is discussed in detailed a digital current control structure based on finite control set model predictive control, permitting an accurate, robust, and faster control of the grid current. A laboratory prototype was developed and experimental tests were performed, verifying the precise operation, and demonstrating the importance of the proposed active rectifier for electrical appliances in smart grids. The results show a low level of current THD, a unitary power factor, and a regulated dc-link voltage.
\end{abstract}

Keywords-Active Rectifier; Three-Level; Two-Switch; Smart Grids; Power Quality; Predictive Control.

\section{INTRODUCTION}

Along the last decades, non-sinusoidal grid currents have been identified as a pertinent problem causing low-levels of power quality. This is more critical nowadays, since the new paradigm of smart grids requires high-levels of power quality for all the grid-connected electrical appliances. A detailed summary concerning the smart grid developments from the point of view of power quality is presented in [1]. In this context, also electric vehicle battery chargers should operate with high-levels of power quality independently of the novelty in terms of operation modes for the integration into smart grids. This is more relevant since EVs represent a new and significant class of electrical appliances for smart grids [2][3]. In [4] and [5] are presented innovative electric vehicle battery chargers, in terms of operational functionalities, and considering high-levels of power quality. An overview and an analysis of power quality for smart grids is presented in [6] and [7], respectively. As a main contribution to mitigate problems associated with power factor and harmonics of current, power factor correction (PFC) topologies that imposing sinusoidal grid currents are a pertinent substitute to diode and multi-pulse rectifiers [8][9]. Considering the different power levels of the grid-connected electrical appliances, many single-phase and three-phase topologies are being presented for a wide range of applications [10][11][12]. As example, the main single and three-phase PFC topologies are identified in [13] and [14], where the most relevant features of each one are explored as a comparison considering the interest for industrial applications.

The classical PFC topology is constituted by a diode full-bridge front-end converter and by a dc-dc boost-type back-end converter used to impose a controlled grid current with low total harmonic distortion (THD) and a controlled output voltage. An evaluation about PFC topologies based on the boost-type converter is presented in [15], where is also included an analysis for the evolution of this converter in terms of improved characteristics [15]. The PFC boost-type is a single-switch two-level topology with a single dc-link voltage. It is important to note that other dc-dc topologies can be applied for the same purpose, however, they have inferior results or more control complexity [16][17][18]. Besides the topologies based on the classical PFC topology, active rectifiers (in some cases also considering a bidirectional operation) are also emerging with an appropriated role to overcome power quality problems in smart grids.

Since the multi-level attribute is an important feature to distinguish PFC (and active rectifier) topologies, the most relevant multi-level PFC topologies (neutral-point-clamped converter, flying-capacitor converter, VIENNA-type converter, SWISS-type converter and cascade converter) are presented in [19], [20], [21], and [22]. Besides the multi-level attribute, PFC topologies can also be classified as interleaved (association of at least two PFCs in parallel) [23], as well as front-end bridgeless converters, i.e., without the full-bridge diode rectifier (differentiated as symmetrical and asymmetrical) [24][25]. A single-phase active rectifier, constituted by a single-switch based on the classical VIENNA rectifier is proposed in [26], where a divided dc-link represents the main disadvantage, since the dc-link voltage must be doubled when compared with the classical PFC. Single-switch PFC topologies are presented in [27] and [28], however, only allowing to establish a controllable power factor, where the high value of THD presented in the grid current is a negative effect for power quality in smart grids.

In this paper, a novel two-switch three-level active rectifier (TSTL-AR) is proposed for grid-connected electrical 
Two-Switch Three-Level (TSTL) converter

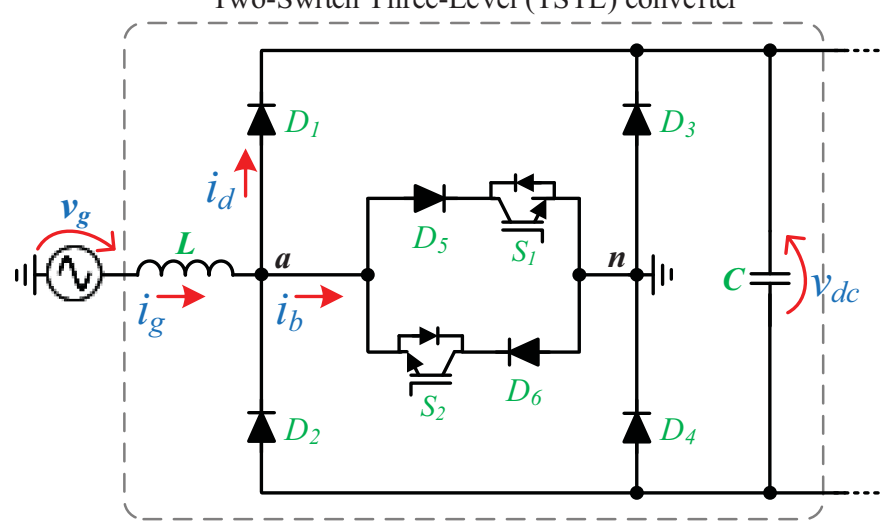

Fig. 1. Proposed single-phase two-switch three-level active rectifier (TSTL-AR) for grid-connected electrical appliances in smart grids.

appliances in smart grids. The circuity of the proposed TSTL-AR is presented in Fig. 1, where it is possible to identify its internal constitution. A classical full-bridge diode rectifier is used as an interface between the power grid and the dc-link. and a bidirectional and bipolar cell is used to establish the zerovoltage level of the converter during both positive and negative half-cycles. The indicated cell is constituted by two switches and two diodes. It noteworthy that the series connections formed by a switch and a diode are controlled independently, i.e., the top $\left(s_{1}\right.$ and $\left.d_{5}\right)$ during the positive half-cycle and the bottom $\left(s_{2}\right.$ and $\left.d_{6}\right)$ during the negative half-cycle. As shown, an inductive filter is used to couple the TSTL-AR to the power grid.

The control algorithm of the proposed TSTL-AR is described in section II. A comprehensive and extensive analysis, including the main simulation results, is presented in section III. An experimental validation of the proposed TSTL-AR, achieved with a developed laboratory prototype, is presented in section IV. Finally, section V summarizes the main conclusions of the work.

\section{CONTROL Algorithm}

The structure of the control algorithm is divided into three fundamental parts, as shown in Fig. 2: (1) Establishment of the reference for the grid current (where is also included the control for the dc-link voltage); (2) Cost function for an optimized tracking between the grid current and its reference; (3) Finite control set model predictive control for the grid current control. The dc-link voltage is regulated using a proportional-integral (PI) controller. As the proposed TSTL-AR operates in single-phase systems, the dc-link voltage has a characteristic oscillation with the double of the power grid frequency. Using the measured dc-link voltage directly in the control algorithm results in a grid current reference with an oscillatory amplitude, and, consequently, the grid current will track its reference. Therefore, to avoid this phenomenon, the mean value of the dc-link voltage is used as an input for the PI controller (the reference for the dc-link voltage keeps constant), resulting in a constant signal as an output of the PI controller. This is valid for the steady-state operation, i.e., changing the operating power (DC load side), the amplitude of the oscillation in the dc-link voltage will also change, changing the

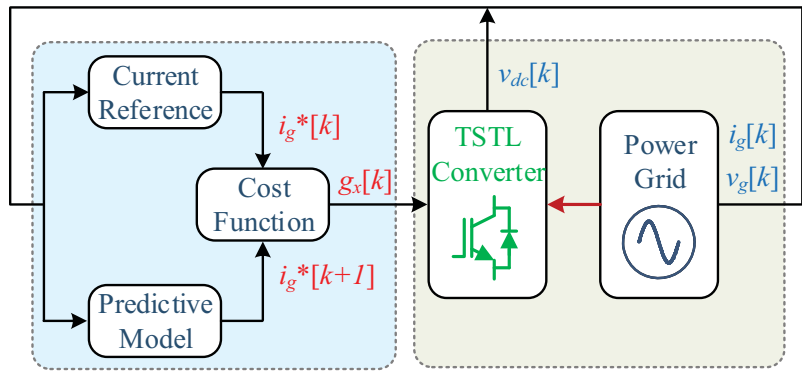

Fig. 2. Structure of the control algorithm.

PI output variable. The reference for the grid current is obtained considering the operating power (measured voltage and current at the dc-side), the output signal from the PI controller, and the power grid voltage. Taking into account that the proposed TSTL-AR converter operates as a linear load, i.e., with a grid current with the same waveform of the power grid voltage. Therefore, it behaves as a resistive load. This can be easily obtained after knowing the values of the active operating power and the root mean square (rms) value of the power grid voltage:

$$
R_{T S T L}=\frac{V_{G}{ }^{2}}{P_{d c}} .
$$

By using the equation (1), the reference for the grid current is established from the following relation:

$$
i_{g}^{*}=\frac{1}{R_{T S T L}} v_{g}
$$

Using this strategy, the grid current has the same waveform of the power grid voltage and it is affected by an amplitude defined in accordance with the nominal operating power. In a smart grid context, this strategy is not totally appropriate to be followed, because the negative effects of the power quality problems that appear in the voltage waveform (mainly the harmonics), will be directly reflected in the grid current. Accordingly, due to the impedances in the grid lines, the THD of current will also contribute to aggravate the THD of voltage. As a key feature to mitigate this aspect, instead of using directly the acquired grid voltage, it is used a phase-locked loop (PLL) in order to obtain a unitary sinusoidal signal in phase with the fundamental component of the input signal, i.e., the power grid voltage. The algorithm proposed in [29] was adopted as a single-phase PLL in the TSTL-AR controller. With the PLL, it is also possible to obtain the rms value of the power grid voltage by using a signal that corresponds to the amplitude of the measured voltage. As a result, by using both signals, it is possible to obtain a sinusoidal signal to be used in the control algorithm:

$$
i_{g}{ }^{*}=\sqrt{2} \frac{P_{d c}}{v_{r m s}} v_{P L L} .
$$

With the reference for the grid current, a predictive strategy based on a finite control set is applied to decide the state of the proposed TSTL-AR during each sampling period of the control algorithm. The basis for the predictive strategy implemented for the TSTL-AR is described in [30] and [31]. This current control strategy was adopted in detriment of other strategies (e.g., linear PI with sinusoidal pulse-width modulation) due to the simplicity of implementation, as well as the robustness for a large range of operating power [30][32]. In the digital 


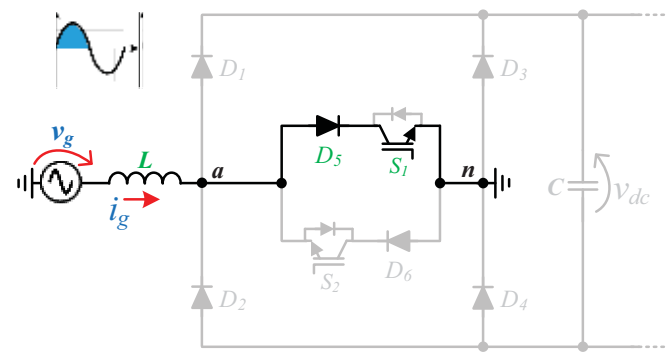

(a)

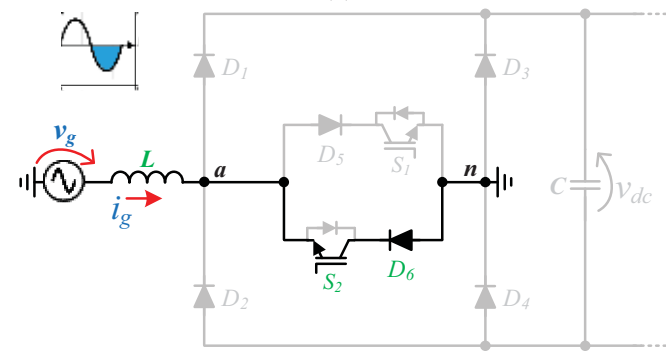

(c)

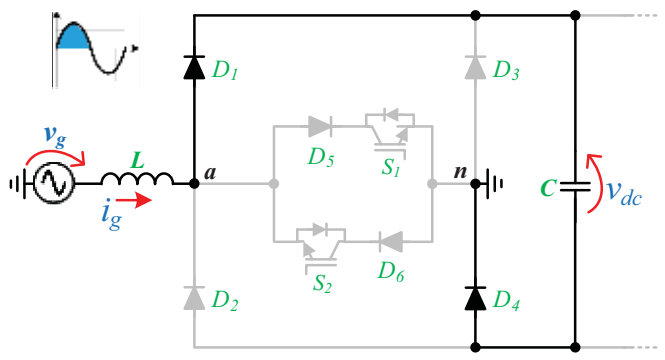

(b)

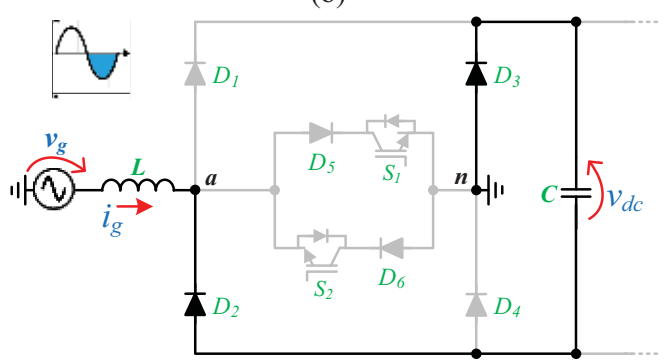

(d)

Fig. 3. Operation stages of the proposed two-switch three-level active rectifier (TSTL-AR): (a)-(b) When $v_{g}>0$; (c)-(d) When $v_{g}<0$.

implementation, the state of the proposed TSTL-AR is decided according to the established reference for the grid current during the period $[k, k+1]$ and the measured current at the instant $[k]$, which stays constant until the instant $k+1$. Applying the voltage Kirchhoff law and the forward Euler method for the voltage across the inductor, the current $i_{g}[k+1]$ is obtained from:

$$
i_{g}[k+1]=\frac{v_{g}[k]-v_{a n}[k]}{f_{s} L}+i_{g}[k],
$$

and the voltage established by the proposed TSTL-AR converter $\left(v_{a n}\right)$, during the period $[k, k+1]$, is decided as a function to minimize the grid current error, i.e., using the quadratic cost function:

$$
g[k+1]=\left\|i_{g}{ }^{*}[k+1]-i_{g}[k+1]\right\|^{2},
$$

where the key objective involves the minimization of the grid current error in steady-state operation. During the positive half-cycle, the voltage $v_{a n}$ can adopt the values of 0 (IGBT $s_{1}$ on and IGBT $s_{2}$ off) or $v_{d c}$ (IGBTs $s_{1}$ and $s_{2}$ off). On the other hand, during the negative half-cycle, the voltage $v_{a n}$ can adopt the values of 0 (IGBT $s_{2}$ on and IGBT $s_{1}$ off) or $-v_{d c}$ (IGBTs $s_{1}$ and $s_{2}$ off). The different states of the proposed TSTL-AR are presented in Fig. 3.

\section{ANALYSIS AND COMPUTATIONAL RESUltS}

This section introduces a computational analysis of the proposed TSTL-AR, in order to validate the proposed control algorithm and to show its dynamic performance. Therefore, a simulation model was developed in the power electronics software PSIM, from PowerSimTech. The main characteristics and parameters used in the simulation model are presented in Table I. The simulation results were acquired with a time-step of $1 \mu \mathrm{s}$. Fig. 4 shows the controlled variables of the proposed TSTL-AR during a steady-state operation. As a consequence of the proposed control algorithm, the grid current $\left(i_{g}\right)$ is sinusoidal and the converter operates with unitary power factor. It should be highlighted that a grid voltage $\left(v_{g}\right)$ having a THD value of $3.9 \%$ was considered as a realistic operating condition for the TSTL-AR. The three distinct voltage levels $\left(v_{a n}\right)$ defined by the TSTL-AR are evidently identified and are in conformity with the following description: during the positive half-cycle the voltage assumes the values of 0 and $+v_{d c}$ and during the negative half-cycle assumes the values of 0 and $-v_{d c}$. In this figure (Fig. 4), it can also be seen that the dc-link voltage is controlled to its reference voltage (in this case $400 \mathrm{~V}$, in order to be superior to the maximum of the power grid voltage), presenting the natural oscillation with the double of the frequency of the power grid voltage.

TABLE I. MAIN CHARACTERISTICS AND PARAMETERS USED IN THE SIMULATION MODEL.

\begin{tabular}{cccc}
\hline \hline CHARACTERISTIC / PARAMETER & LABEL & VALUE & UNIT \\
\hline \hline Power Grid Voltage & $v_{g}$ & 230 & $\mathrm{~V}$ \\
Power Grid Voltage THD & THDv & 3.9 & $\%$ \\
Power Grid Frequency & $f_{g}$ & 50 & $\mathrm{~Hz}$ \\
Maximum Grid Current THD & THDi & 2.5 & $\%$ \\
Maximum Operating Power & $P_{g}$ & 3.5 & $\mathrm{~kW}$ \\
Power Factor & $\mathrm{PF}$ & 0.99 & - \\
Dc-link Voltage & $v_{d c}$ & 400 & $\mathrm{~V}$ \\
Maximum Switching Frequency & $f_{s w}$ & 20 & $\mathrm{kHz}$ \\
Sampling Frequency & $f_{s}$ & 40 & $\mathrm{kHz}$ \\
L Passive Filter (ac-side) & $\mathrm{L}$ & 5 & $\mathrm{mH}$ \\
C Passive Filter (dc-side) & $\mathrm{C}$ & 3 & $\mathrm{mF}$ \\
\hline \hline
\end{tabular}

Aiming to evaluate the dynamic behavior of the proposed TSTL-AR for different operating powers $(1 \mathrm{~kW}, 2.5 \mathrm{~kW}$ and $3.5 \mathrm{~kW}$ ) and its response towards abrupt variations in the operating power, Fig. 5 shows a comprehensive comparison between the grid current $\left(i_{g}\right)$ and its reference $\left(i_{g}{ }^{*}\right)$. Fig. 5(b) shows a comparison when the operating power increases from $1 \mathrm{~kW}$ to $3.5 \mathrm{~kW}$, where the grid current $\left(i_{g}\right)$ reaches its reference with a time delay of $250 \mu$ s, i.e., representing $1.25 \%$ 


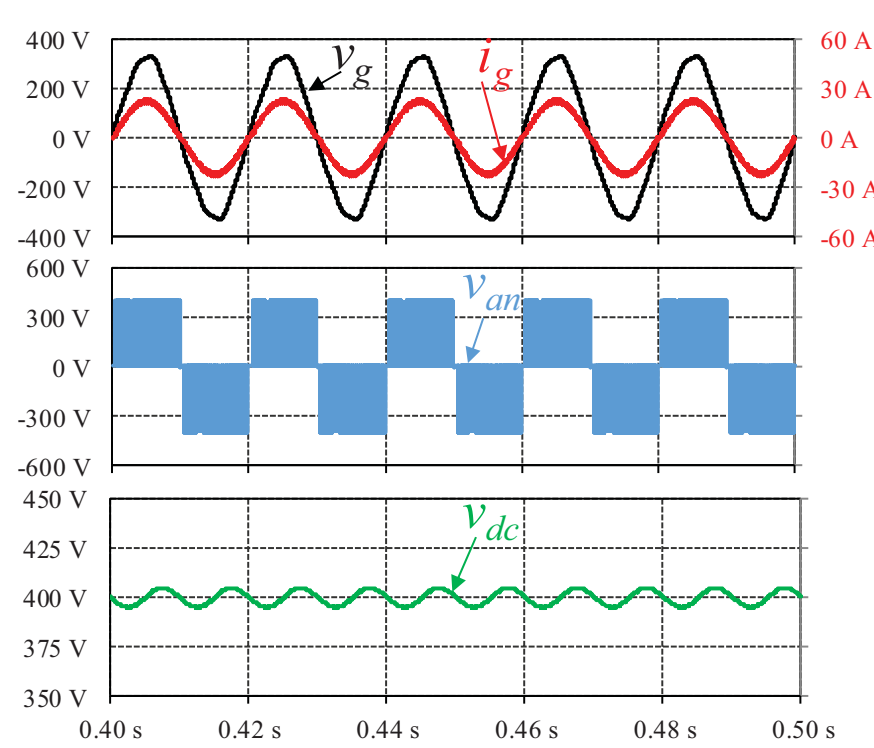

Fig. 4. Main variables of the proposed TSTL-AR during its normal operation: Grid voltage $\left(v_{g}\right)$ and current $\left(i_{g}\right)$; Voltage established downstream the passive filter $\left(v_{a n}\right)$; Voltage at the dc-link $\left(v_{d c}\right)$.

of the voltage period. On the other hand, Fig. 5(c) shows a comparison when the operating power decreases from $3.5 \mathrm{~kW}$ to $2.5 \mathrm{~kW}$, where the grid current $\left(i_{g}\right)$ reaches its reference with a time delay of $500 \mu$ s, i.e., representing $2.5 \%$ of the voltage period. As demonstrated, in both situations (increase and decrease of operating power), the grid current tracks its reference with a fast response and without perturbations affecting the power quality. Moreover, it can be observed a sinusoidal grid current during the three operating power levels, as well as a unitary power factor. A comparison with the classical PFC converter (diode full-bridge ac-dc with a dc-dc boost-type) was established, aiming to verify the estimated efficiency from 0 to a maximum operating power of $3.5 \mathrm{~kW}$. The thermal model for power semiconductors, available in the PSIM software, was used and the same parameters were considered for both converters, as well as similar control algorithms based on a finite control set model predictive. As shown in Fig. 6, the proposed TSTL-AR presents a better-estimated efficiency for all the operating power levels, reaching a maximum efficiency of $95.8 \%$ and representing a relevant topology for grid-connected electrical appliances in smart grids.

\section{EXPERIMENTAL VALIDATION}

This section aims to support the experimental validation of the proposed TSTL-AR and its control algorithm, a dedicated laboratory prototype was developed, including the power and control stages as shown in Fig. 7. The digital control stage is constituted by a C2000 digital signal processor (DSP) from Texas Instruments (model F28335) and by a set of control boards used for the voltages and currents acquisition (through an external analog-to-digital ADC converter), as well as to control the IGBTs drivers. On the other hand, the power stage is constituted by the proposed TSTL-AR with IGBTs from Fairchild Semiconductor (model FGA25N120FTDTU) and fast recovery diodes from Littelfuse Power Semiconductors (model DUR6060W), as well as by IGBT gate-drive

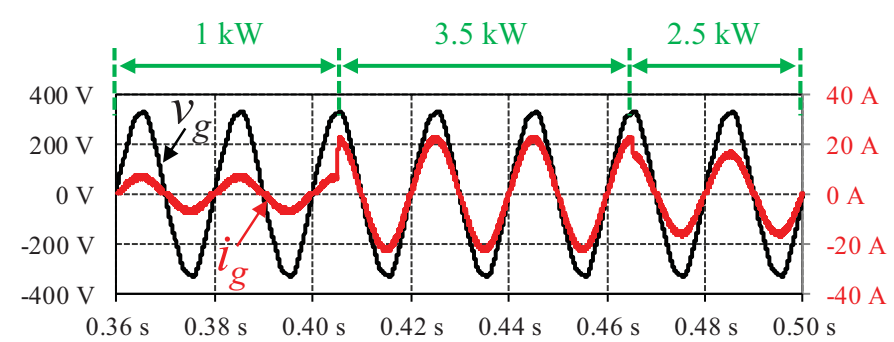

(a)

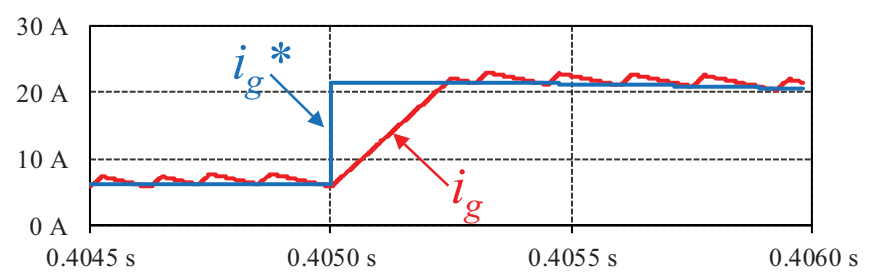

(b)

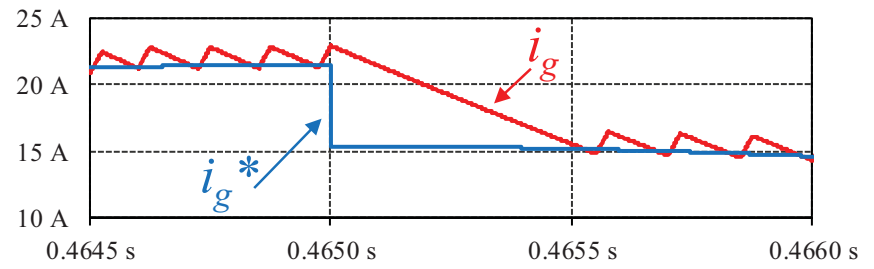

(c)

Fig. 5. Dynamic operation of the proposed TSTL-AR: (a) Overview for different operating powers; (b) Detail of the power increase; (c) Detail of the power decrease.

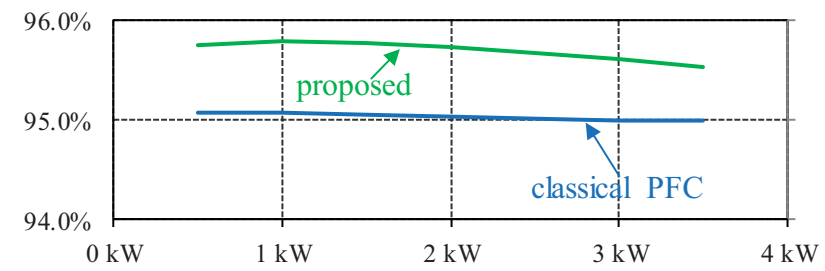

Fig. 6. Comparison in terms of estimated efficiency (from 0 to $3.5 \mathrm{~kW}$ ) between the proposed TSTL-AR and the classical PFC.

optocouplers from Avago (model HCPL3120) and Hall-effect voltage and current transducers.

The digital control algorithm, implemented in a low-level $\mathrm{C}$ code, is executed with a sampling frequency of $40 \mathrm{kHz}$. The time required to implement the core tasks of the control algorithm is presented in Table II. The digital filter to extract the mean value of the dc-link voltage is the task that requires more time to be executed, and the cost function is the faster task implemented. Through a power quality analyzer from Fluke (model 435), Fig. 8 shows the spectral analysis and the THD value of the grid current. The results shown in Fig. 8(a) were obtained before the IGBTs turn-on, i.e., only considering the operation of the diode-bridge rectifier, and the results in Fig. 8(b) were obtained after the IGBTs turn-on. As it can be seen, the $3^{\text {th }}, 5^{\text {th }}$, and $7^{\text {th }}$ harmonics were practically eliminated and the THD was reduced from $59.9 \%$ to $6.3 \%$, validating the advantages of the proposed TSTL-AR. Fig. 9(a) shows the experimental results in the ac-side, illustrating that the grid current $\left(i_{g}\right)$ has a sinusoidal waveform, even when it is connected to a power grid with a significant voltage $\left(v_{g}\right)$ THD 


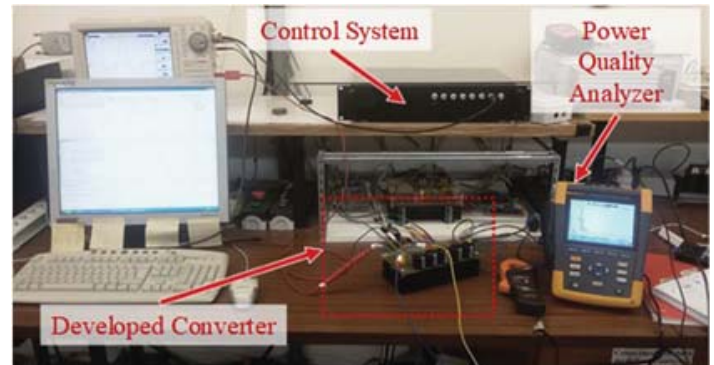

(a)

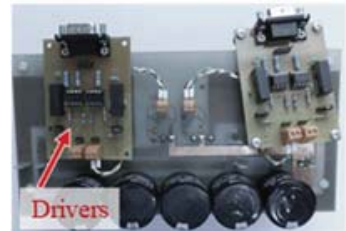

(b)

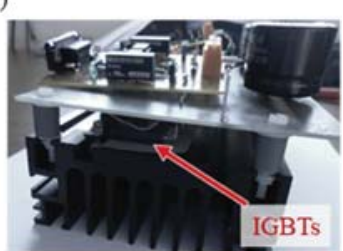

(c)
Fig. 7. Developed system: (a) Laboratorial workbench; (b) Developed TSTS-AR prototype; (c) Detail of the developed TSTS-AR prototype.

TABLE II. Time ReQuiRed to IMPLEMENT the CONTROL AlgORITHM.

\begin{tabular}{cc}
\hline \hline TASK & TIME \\
\hline \hline Signals acquisition from ADCs & $0.69 \mu \mathrm{s}$ \\
PLL implementation & $0.82 \mu \mathrm{s}$ \\
Digital filter for the dc-link voltage & $0.90 \mu \mathrm{s}$ \\
Dc-link voltage control & $0.55 \mu \mathrm{s}$ \\
Establishment for the current reference & $0.82 \mu \mathrm{s}$ \\
Cost Function & $0.50 \mu \mathrm{s}$ \\
IGBTs state selection & $0.80 \mu \mathrm{s}$ \\
\hline \hline
\end{tabular}

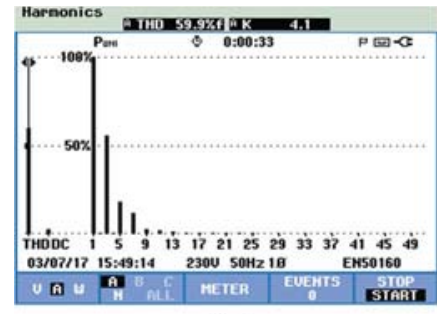

(a)

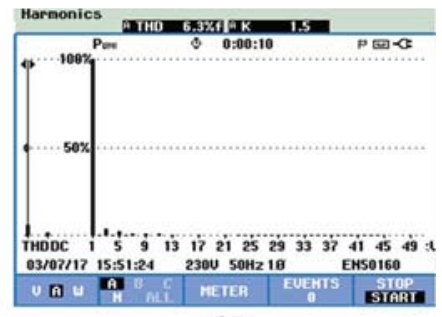

(b)
Fig. 8. Spectral analysis and THD value of the grid current: (a) Before the IGBTs turn on; (b) After the IGBTs turn on.

value. As expected, both variables are in phase, meaning an operation with a unitary power factor. A detail of the grid current in contrast with the gate-emitter voltage of the IGBT $s_{1}$ is presented in Fig. 9(b).

In this experimental result, it is possible to identify the non-fixed switching frequency, which is a natural characteristic of the finite control set model predictive control. In this detailed case, a maximum switching frequency of $10 \mathrm{kHz}$ was measured. In order to verify the gate signals of the IGBTs during a period of the power grid voltage $(20 \mathrm{~ms})$, Fig. 10 shows the grid current $\left(i_{g}\right)$, the gate-emitter voltage of both IGBTs $s_{1}$ and $s_{2}$, and the power grid voltage $\left(v_{g}\right)$. As shown, the obtained results are in accordance with the described operation in the control algorithm?m, i.e., the IGBT $s_{l}$ is switched during the positive half-cycle and the IGBT $s_{2}$ is switched in the other half-cycle.
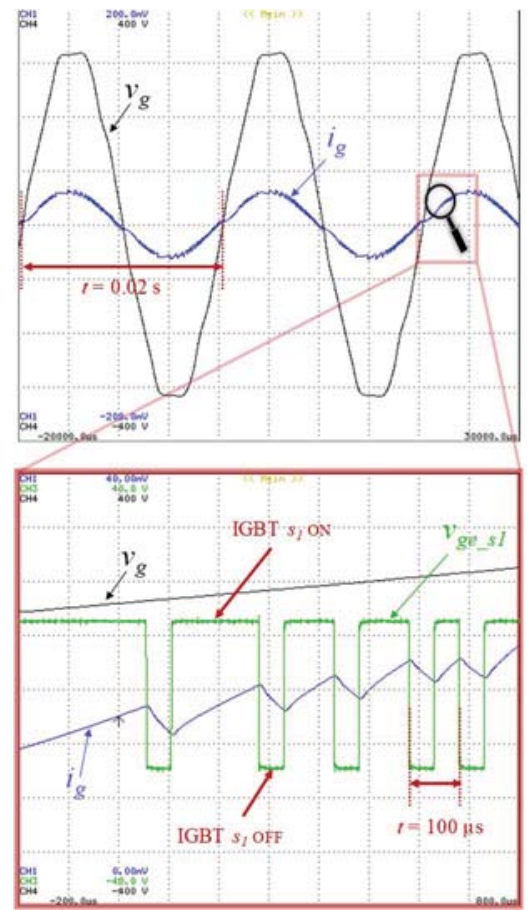

Fig. 9. Experimental results: Grid voltage $\left(v_{g}\right)$, grid current $\left(i_{g}\right)$ and gate-emitter voltage of the IGBT $s_{1}\left(v_{\text {gess }}\right)$.

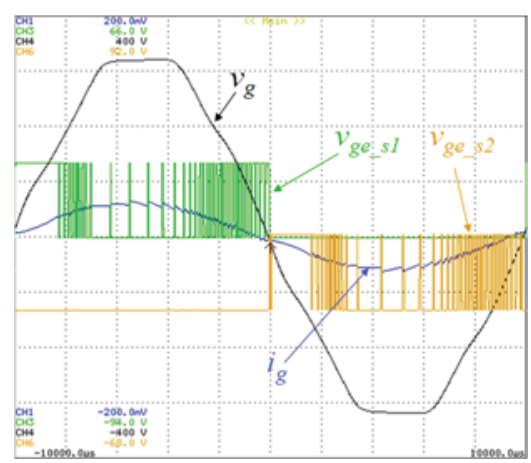

Fig. 10. Experimental results: Grid voltage $\left(v_{g}\right)$, grid current $\left(i_{g}\right)$, gate emitter voltage of the IGBT $s_{1}\left(v_{g e_{-} s}\right)$ and gate emitter voltage of the IGBT $s_{2}\left(v_{g e-s}\right)$.

\section{CONCLUSION}

A novel two-switch three-level active rectifier (TSTL-AR) is proposed as an important contribution to ensure power quality aspects of grid-connected electrical appliances in smart grids. The principle of operation is presented in detail along the paper, including an exhaustive description about the control algorithm, mainly, based on the dc-link voltage control, the reference for the grid current, and the predictive current control. A laboratory prototype was developed and an experimental validation was performed, allowing to acquire the most relevant results. As demonstrated along the paper, the proposed TSTL-AR operates with sinusoidal grid current, reduced value of total harmonic distortion, controlled dc-link voltage, and unitary power factor, representing an attractive alternative for the classical PFC converter for grid-connected electrical appliances in smart grids. 


\section{ACKNOWLEDGMENT}

This work has been supported by COMPETE: POCI-010145-FEDER-007043 and FCT - Fundação para a Ciência e Tecnologia within the Project Scope: UID/CEC/00319/2013. This work is financed by the ERDF - European Regional Development Fund through the Operational Programme for Competitiveness and Internationalisation - COMPETE 2020 Programme, and by National Funds through the Portuguese funding agency, FCT - Fundação para a Ciência e a Tecnologia, within project SAICTPAC/0004/2015 - POCI 01-0145-FEDER-016434.

\section{REFERENCES}

[1] Math H. J. Bollen, Jin Zhong, Francisc Zavoda, Jan Meyer, Alex McEachern, Felipe Córcoles López, "Power Quality aspects of Smart Grids," ICREPQ International Conference on Renewable Energies and Power Quality, pp.1-6, Mar. 2010.

[2] Vitor Monteiro, João C. Ferreira, Andres A. Nogueiras Melendez, Carlos Couto, João L. Afonso, "Experimental Validation of a Novel Architecture Based on a Dual-Stage Converter for Off-Board Fast Battery Chargers of Electric Vehicles," IEEE Trans. Veh. Tech., vol.67, no.2, pp.1000-1011, Feb. 2018.

[3] Vítor Monteiro, Henrique Gonçalves, João L. Afonso, "Impact of Electric Vehicles on Power Quality in a Smart Grid Context," IEEE EPQU International Conference on Electrical Power Quality and Utilisation, pp.1-6, Oct. 2011

[4] Vítor Monteiro, J. G. Pinto, João L. Afonso, "Operation Modes for the Electric Vehicle in Smart Grids and Smart Homes: Present and Proposed Modes," IEEE Trans. Veh. Tech., vol.65, no.3, pp.1007-1020, Mar. 2016.

[5] Vítor Monteiro, Bruno Exposto, João C. Ferreira, João L. Afonso, "Improved Vehicle-to-Home (iV2H) Operation Mode: Experimental Analysis of the Electric Vehicle as Off-Line UPS," IEEE Transactions on Smart Grid, vol.8, no.6, pp.2702-2711, Nov. 2017.

[6] An Luo, Qianming Xu, Fujun Ma, Yandong Chen, "Overview of Power Quality Analysis and Control Technology for the Smart Grid," SPRINGER Journal of Modern Power Systems and Clean Energy, vol.4, no.1, pp.1-9, Jan. 2016

[7] Oana Ceaki, George Seritan, Ramona Vatu, Monica Mancasi, “Analysis of Power Quality Improvement in Smart Grids," International Symposion on Advanced Topics in Electrical Engineering, pp.797-801, Bucharest Romania, Mar. 2017.

[8] Oscar García, José A. Cobos, Roberto Pietro, Pedro Alou, Javier Uceda, "Single Phase Power Factor Correction: A Survey," IEEE Trans. Power Electron., vol.18, no.3, pp.749-755, May 2003.

[9] Vítor Monteiro, Andrés A. Nogueiras Meléndez, João C. Ferreira, Carlos Couto, João L. Afonso, "Experimental Validation of a Proposed Single-Phase Five-Level Active Rectifier Operating with Model Predictive Current Control,“ IEEE IECON Industrial Electronics Conference, pp.3939-3944, Nov. 2015.

[10] Bhim Singh, Brij N. Singh, Ambrish Chandra, Kamal Al-Haddad, Ashish Pandey, Dwarka P. Kothari, "A Review of Single-Phase Improved Power Quality AC-DC Converters," IEEE Trans. Ind. Electron., vol.50, no.5, pp.962-981, Oct. 2003.

[11] Vítor Monteiro, Andrés A. Nogueiras Meléndez, Carlos Couto, João L. Afonso, "Model Predictive Current Control of a Proposed SingleSwitch Three-Level Active Rectifier Applied to EV Battery Chargers," IEEE IECON Industrial Electronics Conference, Florence Italy, pp.1365-1370, Oct. 2016.

[12] Bhim Singh, Brij N. Singh, Ambrish Chandra, Kamal Al-Haddad, Ashish Pandey, Dwarka P. Kothari, "A Review of Three-Phase Improved Power Quality AC-DC Converters," IEEE Trans. Ind. Electron., vol.51, no.3, pp.641-660, June 2004.

[13] Johann W. Kolar, Thomas Friedli, "The Essence of Three-Phase PFC Rectifier Systems-Part I," IEEE Trans. Power Electron., vol.28, no.1, pp.176-198, Jan. 2013.
[14] Thomas Friedli, Michael Hartmann, Johann W. Kolar, , "The Essence of Three-Phase PFC Rectifier Systems-Part II," IEEE Trans. Power Electron., vol.29, no.2, pp.543-560, Feb. 2014.

[15] João Paulo M. Figueiredo, Fernando L. Tofoli, Bruno Leonardo A. Silva, "A Review of Single-Phase PFC Topologies Based on The Boost Converter," IEEE INDUSCON International Conference on Industry Applications, pp.1-6, Nov. 2010.

[16] Huai Wei, Issa Batarseh, "Comparison of Basic Converter Topologies for Power Factor Correction," IEEE Proceedings of Southeastcon, pp.348-353, Apr. 1998.

[17] Bo-Tao, Yim-Shu Lee, "Power-Factor Correction Using Cuk Converters in Discontinuous-Capacitor-Voltage Mode Operation," IEEE Trans. Ind. Electron., vol.44, no.5, pp648-653, Oct. 1997.

[18] Grover Victor Torrico-Bascopé, Ivo Barbi, "A Single Phase PFC 3 kW Converter Using a Three-State Switching Cell," IEEE Power Electronics Specialists Conference, vol.5, pp.4037-4042, June 2004.

[19] Akira Nabae, Isao Takahashi, Hirofumi Akagi, "A New Neutral-PointClamped PWM Inverter,” IEEE Trans. Ind. Appli., vol.IA-17, no.5, pp.518-523, Sept. 1981.

[20] Vítor Monteiro, Andrés A. Nogueiras Meléndez, João L. Afonso, "Novel Single-Phase Five-Level VIENNA-Type Rectifier with Model Predictive Current Control,“ IEEE IECON Industrial Electronics Conference, pp.6413-6418, Nov. 2017.

[21] Johann W. Kolar, Franz C. Zach,“A Novel Three-Phase Utility Interface Minimizing Line Current Harmonics of High-Power Telecommunications Rectifier Modules," IEEE Trans. Ind. Electron., vol.44, no.4, pp.456-467, Aug. 1997.

[22] T. B. Soeiro, T. Friedli, J. W. Kolar, "SWISS Rectifier - A Novel Three-Phase Buck-Type PFC Topology for Electric Vehicle Battery Charging," IEEE APEC Applied Power Electronics Conference and Exposition, pp.2617-2624, Orlando USA, Feb. 2012.

[23] Fernando Beltrame, Leandro Roggia, Luciano Schuch, José Renes Pinheiro, "A Comparison of High Power Single-Phase Power Factor Correction Pre-Regulators," IEEE ICIT Industrial Technology, pp.625630, Mar. 2010.

[24] Roberto Martinez, Prasad N. Enjeti, "A High-Performance Single-phase Rectifier with Input Power Factor Correction," IEEE Trans. Power Electron., vol.11, no.2, pp.311-317, Mar. 1996.

[25] Jee-Woo Lim, Bong-Hwan Kwon, "A Power-Factor Controller for Single-Phase PWM Rectifiers," IEEE Trans. Ind. Electron., vol.46, no.5, pp.1035-1037, Oct. 1999.

[26] Hani Vahedi, Philippe-Alexandre Labbé, Kamal Al-Haddad, "SinglePhase Single-Switch Vienna Rectifier as Electric Vehicle PFC Battery Charger," IEEE VPPC Vehicle Power and Propulsion Conference, pp.16, Oct. 2015.

[27] Chien-Ming Wang, "A Novel Single-Switch Single-Stage Electronic Ballast With High Input Power Factor,” IEEE Trans. Power Electron., vol.22, no.3, pp.797-803, May 2007.

[28] Jong-Jae Lee, Jung-Min Kwon, Eung-Ho Kim,Woo-Young Choi, BongHwan Kwon, "Single-Stage Single-Switch PFC Flyback Converter Using a Synchronous Rectifier," IEEE Trans. Ind. Electron., vol.55, no.3, pp.1352-1365, Mar. 2008.

[29] M. Karimi-Ghartemani, M. R. Iravani, "A Nonlinear Adaptive Filter for Online Signal Analysis in Power Systems: Applications," IEEE Trans. Power Del., vol.17, no.2, pp.617-622, Apr. 2002.

[30] Vítor Monteiro, João C. Ferreira, Andrés A. Nogueiras Meléndez, João L. Afonso, "Model Predictive Control Applied to an Improved FiveLevel Bidirectional Converter," IEEE Trans. Ind. Electron., vol.63, no.9, pp.5879-5890, Sept. 2016.

[31] Samir Kouro, Patricio Cortés, René Vargas, Ulrich Ammann, José Rodríguez, "Model Predictive Control - A Simple and Powerful Method to Control Power Converters," IEEE Trans. Ind. Electron., vol.56, no.6, pp.1826-1838, June 2009.

[32] Vítor Monteiro, João C. Ferreira, Delfim Pedrosa, João L. Afonso, "Comprehensive Analysis and Comparison of Digital Current Control Techniques for Active Rectifiers," CONTROLO Portuguese Conference on Automatic Control, Guimarães - Portugal, pp.655-666, Sept. 2016. 